\title{
Differential Performance of a Specialist and Two Generalist Herbivores and Their Parasitoids on Plantago lanceolata
}

\author{
Joanneke H. Reudler • Arjen Biere • Jeff A. Harvey • \\ Saskya van Nouhuys
}

Received: 28 February 2011 / Revised: 3 June 2011 /Accepted: 8 June 2011 /Published online: 21 June 2011

(C) The Author(s) 2011. This article is published with open access at Springerlink.com

\begin{abstract}
The ability to cope with plant defense chemicals differs between specialist and generalist species. In this study, we examined the effects of the concentration of the two main iridoid glycosides (IGs) in Plantago lanceolata, aucubin and catalpol, on the performance of a specialist and two generalist herbivores and their respective endoparasitoids. Development of the specialist herbivore Melitaea cinxia was unaffected by the total leaf IG concentration in its host plant. By contrast, the generalist herbivores Spodoptera exigua and Chrysodeixis chalcites showed delayed larval and pupal development on plant genotypes with high leaf IG concentrations, respectively. This result is in line with the idea that specialist herbivores are better adapted to allelochemicals in host plants on which they are specialized. Melitaea cinxia experienced less post-diapause larval and pupal mortality on its local Finnish P. lanceolata
\end{abstract}

J. H. Reudler · A. Biere · J. A. Harvey

Department of Terrestrial Ecology,

Netherlands Institute of Ecology, NIOO-KNAW,

P.O. Box 50, NL-6700 AB Wageningen, The Netherlands

S. van Nouhuys

Department of Ecology and Evolutionary Biology,

Cornell University,

Corson Hall,

Ithaca, NY 14853, USA

S. van Nouhuys

Department of Biosciences, University of Helsinki,

FIN-00014 Helsinki, Finland

Present Address:

J. H. Reudler $(\bowtie)$

Centre of Excellence in Evolutionary Research, Department of

Biological and Environmental Sciences, University of Jyväskylä,

P.O. Box 35, FI-40014 Jyväskylä, Finland

e-mail: talsma.reudler@jyu.fi than on Dutch genotypes. This could not be explained by differences in IG profiles, suggesting that $M$. cinxia has adapted in response to attributes of its local host plants other than to IG chemistry. Development of the specialist parasitoid Cotesia melitaearum was unaffected by IG variation in the diet of its host $M$. cinxia, a response that was concordant with that of its host. By contrast, the development time responses of the generalist parasitoids Hyposoter didymator and Cotesia marginiventris differed from those of their generalist hosts, S. exigua and $C$. chalcites. While their hosts developed slowly on high-IG genotypes, development time of $H$. didymator was unaffected. Cotesia marginiventris actually developed faster on hosts fed high-IG genotypes, although they then had short adult longevity. The faster development of $C$. marginiventris on hosts that ate high-IG genotypes is in line with the "immunocompromized host" hypothesis, emphasizing the potential negative effects of toxic allelochemicals on the host's immune response.

Key Words Chemical defense - Chrysodeixis chalcites . Cotesia marginiventris · Cotesia melitaearum · Hyposoter didymator - Immunocompromised host - Iridoid glycosides . Melitaea cinxia $\cdot$ Multitrophic interactions .

Spodoptera exigua

\section{Introduction}

Plants have evolved a wide array of direct defenses against herbivores and diseases. Direct defenses include morphological traits (Cooper and Owen-Smith, 1986), and chemical toxins, repellents, or digestibility reducers (Fraenkel, 1959; Ehrlich and Raven, 1964). These defenses not only affect the performance of herbivores 
but also can have positive or negative effects on natural enemies of herbivores. Positive effects of chemical defense in the herbivore's diet on natural enemies can arise in several ways. For instance, allelochemicals may slow down the growth rate of the herbivore, extending the time window during which the herbivore is vulnerable to parasitism or predation by its natural enemies (Clancy and Price, 1987). Toxic allelochemicals also may weaken host immune responses, making them more susceptible to parasitation or predation (Nappi, 1975; Smilanich et al., 2009). On the other hand, allelochemicals can have negative effects on the growth, development, or survival of predators and parasitoids (Gunasena et al., 1990; Paradise and Stamp, 1993; Harvey et al., 2007b). For instance, hosts may actively sequester these compounds in their haemolymph where they can again function as defense (Bowers, 1980, 1981; Camara, 1997b; Nishida, 2002).

The ability of herbivores to cope with plant allelochemicals varies among species that differ in their dietary range. Polyphagous species (generalists) feed on many species in a range of plant families (Bowers and Puttick, 1988; Agrawal, 2000). Even though many herbivores are polyphagous at the species level, they are not necessarily so at the population or individual level since species can be comprised of populations or individuals that are specialized on a few or even a single food plant (Singer, 2008). Some studies support the idea that detoxification systems of generalists are capable of accepting a more structurally diverse array of compounds than those of specialists (Li et al., 2004) at the expense of a less efficient detoxification of individual compounds (Johnson, 1999). Oligophagous species (specialists) often are physiologically adapted to the nutritional and secondary chemistry of particular plant species (Renwick et al., 2001; Cornell and Hawkins, 2003). They may use the allelochemicals to which they have adapted as host-finding cues and feeding stimulants (Rhoades, 1979; Bowers, 1981). A number of specialist herbivores sequester these substances as defense against their own natural enemies (Bowers, 1981), which requires physiological or morphological adaptations to prevent autotoxicity (Duffey, 1980).

The division between generalists and specialists also can be made for predators and parasitoids of herbivores. Allelochemicals present in herbivores, or in the diet of an herbivore, can reduce the performance of generalist predators and parasitoids (e.g., Duffey et al., 1986; Gunasena et al., 1990). Generalist parasitoids may attack a wide range of herbivorous host species that feed on plants with different defensive chemistry. These parasitoids may suffer during development if their hosts are able to sequester or accumulate plant derived compounds, to which they are not adapted (Barbosa, 1988; Barbosa et al., 1991; Harvey et al., 2005). In contrast, specialized natural enemies, such as many endoparasitoid wasps, are restricted to attacking only one or a few related host species, which generally feed on closely related plants (Godfray, 1994; Quicke, 1997). These parasitoids may be adapted to the limited set of chemicals to which they are exposed (Harvey et al., 2005), allowing them to use hosts that sequester specific plant chemical defenses (Barbosa et al., 1986; Sznajder and Harvey, 2003; Harvey et al., 2007a,b).

The types and concentrations of defensive substances found in plant tissues vary greatly among plant species as well as among individuals of the same species (Denno and McClure, 1983; Nieminen et al., 2003). In this study, we used genotypes of ribwort plantain [Plantago lanceolata L. (Plantaginaceae)] that differ in constitutive concentrations of two iridoid glycosides (IGs), aucubin and catalpol, to study the effects of allelochemical variation on specialist and generalist herbivore-parasitoid associations. Iridoid glycosides are monoterpenoids. Aucubin is the biosynthetic precursor of catalpol (Damtoft et al., 1983). The concentrations of IGs in P. lanceolata show large natural variation among individuals, and within individuals over time (Bowers and Stamp, 1992; Darrow and Bowers, 1997; Barton, 2007). Aucubin, and to a greater extent catalpol, are toxic or deterrent to generalists (Puttick and Bowers, 1988; Bowers, 1991). At the same time, these compounds serve as feeding and oviposition stimulants for some specialist herbivores (Bowers, 1984; Pereyra and Bowers, 1988; Nieminen et al., 2003; Reudler Talsma et al., 2008). Larvae and adults of the specialist butterflies Melitaea cinxia (Lepidoptera: Nymphalidae) and Junonia coenia (Lepidoptera: Nymphalidae) sequester aucubin and catalpol (Bowers and Collinge, 1992; Suomi et al., 2001, 2003). Larvae of $J$. coenia do this more efficiently than polyphagous insect herbivores (Lampert and Bowers, 2010), and they sequester catalpol more efficiently than aucubin (Bowers and Collinge, 1992). The latter is also observed for larvae of M. cinxia and Parasemia plantaginis (Lepidoptera: Arctiidae) (Reudler Talsma, unpublished). Only few studies have assessed the effect of these compounds on preference or performance of parasitoids, using dipteran (Mallampalli et al., 1996) or hymenopteran parasitoids (Nieminen et al., 2003; Harvey et al., 2005; Lampert et al., 2010). Our study extends that of Harvey et al. (2005) by including two generalist herbivores, each with two generalist parasitoids, to investigate whether effects of IG are consistent across these generalist systems, and compares them with a specialist system. Moreover, we include a series of plant genotypes that span a wide range of mean IG concentrations in order to gain quantitative insight into associations between plant IGs and insect development parameters.

We address the following questions: (1) Is the performance of herbivores and their parasitoids affected 
by the concentrations of the iridoid glycosides aucubin and catalpol in P. lanceolata? (2) Are there consistent differences in the effect of plant iridoid glycosides on the performance of specialist vs. generalist herbivores and parasitoids?

\section{Methods and Material}

\section{Plants}

Plantago lanceolata is a perennial plant with a worldwide distribution (Sagar and Harper, 1964). In natural populations, IG levels range from undetectable to ca. $12 \%$ of the plant dry weight (Bowers et al., 1992; Fajer et al., 1992). There generally is no correlation between IG concentrations (aucubin or catalpol) and tissue nutrient concentrations (Marak et al., 2000; Reudler Talsma, 2007). Plants used for our experiments came from two sources. Thirteen genotypes, used in all experiments, were derived from an artificial selection experiment in which lines were selected for high and low leaf IG concentrations for four generations, originating from Dutch P. lanceolata (Marak et al., 2000). These genotypes, each originating from a different half-sib family, were clonally propagated (Wu and Antonovics, 1975) in order to generate sufficient leaf material of each genotype. For experiments involving the specialist butterfly M. cinxia and its specialist endoparasitoid Cotesia melitaearum, (Hymenoptera: Braconidae), we augmented this set of genotypes with three additional genotypes from the selection experiment, and ten genotypes collected from Åland, Finland [where the insects originated (see below)]. We tested the effects of quantitative variation in allelochemicals in the plants on the development of six different insect species: two generalist herbivores, two generalist endoparasitoids reared on each of these generalist herbivores, and a specialist herbivore and its specialist endoparasitoid.

\section{Herbivores}

Generalists The beet armyworm, Spodoptera exigua (Lepidoptera: Noctuidae), is polyphagous, and a serious pest of many crops worldwide. Females lay several clusters of $50-100$ eggs that hatch within $2-3 \mathrm{~d}$. The larvae normally have five instars (the first three are gregarious), and the entire life cycle is about $4-5$ weeks with several generations per year (Wilson, 1934; Tingle and Mitchell, 1977). Cultures of S. exigua were established from eggs originating from a laboratory culture maintained on artificial diet at the Department of Virology at Wageningen University, the Netherlands.

The golden twin spot, Chrysodeixis chalcites (Lepidoptera: Noctuidae) is native to Central and Southern Europe, the Canary Islands, and Africa. Like S. exigua, it is a polyphagous crop pest. Eggs are laid singly or in small groups and hatch in 4-9 d. The larvae normally complete 6 instars and the entire life cycle is completed in about 5-7 weeks (Goodey, 1991). Chrysodeixis chalcites cultures were established from individuals collected from a garden in Nijmegen, the Netherlands.

Cultures of both S. exigua and C. chalcites were kept as caterpillars in plastic Petri dishes on artificial diet (Elzinga, 2002) at $25^{\circ} \mathrm{C}$ and $16: 8 \mathrm{~h} \mathrm{~L}: \mathrm{D}$. When caterpillars were in their final instar, they were placed in plastic containers $(15 \times 10 \times 10 \mathrm{~cm})$ with diet and vermiculite into which they pupated. In order to get larvae for the experiment, adult moths were placed in a cage $(40 \times 50 \times 65 \mathrm{~cm})$ in a climate room at $25^{\circ} \mathrm{C}, 55 \% \mathrm{RH}$ and $16: 8 \mathrm{~h} \mathrm{~L}: \mathrm{D}$ with honey water $(1: 1)$ and one $P$. lanceolata plant, that both noctuid species readily accepted for oviposition. Newly hatched caterpillars were collected from this cage and reared in Petri dishes $(8 \mathrm{~cm})$ on artificial diet until they reached their 3rd instar, after which they were used in the performance studies. The early growth on artificial diet was done in order to have sufficient numbers of caterpillars for the experiments, as their $1 \mathrm{st}$ instars survive better on artificial diet than on P. lanceolata diet (personal observation). Note that since the artificial diet contains no IGs, the effect of IG on larval and parasitoid performance is limited to what was ingested as later instars.

Specialist The Glanville fritillary butterfly, M. cinxia, inhabits open grasslands in parts of Europe and temperate Asia. It has one generation per year in most of its range. A female lays several large egg clusters (150-200) on plants in the genera Plantago and Veronica (Plantaginaceae) (Kuussaari et al., 2004). Larvae spin a communal web and feed gregariously throughout most of their development. Higher levels of IGs in the diet can increase the rate of development (Harvey et al., 2005; Saastamoinen et al., 2007). Furthermore, IGs are sequestered by the larvae (Suomi et al., 2001, 2003), and plants with higher IG levels are preferred for oviposition (Nieminen et al., 2003; Reudler Talsma et al., 2008). Melitaea cinxia caterpillars used for these experiments were the offspring of laboratory reared butterflies from Åland, SW Finland. The caterpillars were fed field collected P. lanceolata leaves until their $3 \mathrm{rd}$ instar when they were used for the experiment. Note that since rearing of $M$. cinxia on specific plant genotypes did not start until they reached their 3rd instar, assessment of effects of IG concentration on larval and parasitoid performance is limited to what was ingested as later instars.

Parasitoids

Generalists Hyposoter didymator (Thunberg, 1822) (Hymenoptera: Ichneumonidae) is a generalist solitary endoparasi- 
toid of caterpillars of many species in the large Lepidoptera family Noctuidae (Bar et al., 1979; Ingram, 1981; Vinson, 1990; Figueiredo et al., 2000; Schneider et al., 2003). This species is a tissue feeder, so the developing wasp larva consumes the entire host. Hyposoter didymator adults were obtained from a laboratory colony that was started in 1993 with wasps collected from parasitized Spodoptera littoralis in the Cordoba, Spain. For 4 years, they were reared on S. frugiperda in the Laboratoire de Pathologie Comparée at INRA UMII, Saint-Christol-lèz-Alés, France. Adults used in the experiment were reared on S. exigua. In order to extend longevity of the adult wasps, they were kept at $10^{\circ} \mathrm{C}$ and $16: 8 \mathrm{~h} \mathrm{~L}: \mathrm{D}$.

Cotesia marginiventris (Cresson, 1865) (Hymenoptera: Braconidae) also is a generalist solitary endoparasitoid that attacks Noctuidae (Krombein et al., 1979). As other Cotesia, the larva feeds primarily on host haemolymph and fat body during its development, and it does not consume the entire host (Sznajder and Harvey, 2003). Cotesia marginiventris were obtained from a colony maintained at Nijmegen University, The Netherlands, where they were reared on $S$. exigua. Adults were kept at $10^{\circ} \mathrm{C}$ and 16:8 h L:D and were constantly provided with honey and water.

Specialist Cotesia melitaearum agg. is a complex of cryptic species specialized on Melitaea or Euphydryas butterflies (Kankare and Shaw, 2004). The species of C. melitaearum agg. used in this study is restricted to the host M. cinxia (Kankare et al., 2005). The adult female parasitoid lays broods of 1-40 eggs (depending on host size) in all instars of $M$. cinxia larvae. We used C. melitaearum from Åland, SW Finland, where the wasp has 2-3 generations per year (Lei et al., 1997). For the experiment, laboratory reared $M$. cinxia caterpillars were put on potted plants that were placed in natural populations in Åland, where they were parasitized by naturally occurring $C$. melitaearum.

\section{Experimental Design}

Generalists Third instars of the two generalist herbivores, $S$. exigua and C. chalcites, were randomly assigned to one of three treatments: unparasitized (control), parasitized by $C$. marginiventris, or parasitized by $H$. didymator. For parasitism, a 3rd instar caterpillar was offered to a female parasitoid, and oviposition was observed as a single insertion of the ovipositor. Although the parasitoids attack all larval instars of $S$. exigua and $C$. chalcites, previous studies have shown that $H$. didymator has the highest reproductive success when it parasitizes 3rd instar hosts (Reudler Talsma et al., 2007). For each P. lanceolata genotype, 16-20 parasitized and 16-20 unparasitized caterpillars of each herbivore species were reared individually on freshly excised leaves in Petri dishes (55 mm diam) in a growth cabinet at $25^{\circ} \mathrm{C}, 16: 8 \mathrm{~h} \mathrm{~L}: \mathrm{D}$ and $70 \% \mathrm{RH}$. The total number of larvae included in the experiment was 451 . Leaves were refreshed every day. This was done using young to intermediate-aged leaves from at least five different plant individuals per genotype. Leaves were collected and then pooled per genotype and distributed across the larvae assigned to that genotype. Due to insufficient leaf production by some of the genotypes, not all genotypes were represented in every treatment combination. Emerged adults (both butterflies and parasitoids) were provided with water and kept at $25^{\circ} \mathrm{C}, 16: 8 \mathrm{~h} \mathrm{~L}: \mathrm{D} ; 70 \% \mathrm{RH}$. The following fitness correlates were recorded for the unparasitized caterpillars: larval development time (the number of days from the 3rd instar, when the experiment started, until pupation), pupal development time, pupal mass, pupal survival until adulthood, adult mass, and adult longevity. The same parameters were recorded for the parasitoids, except that larval development time was recorded from the day of parasitism until the larva emerged from the host, and pupal development time was the number of days between larval emergence and adult wasp eclosion. Pupal mass of parasitoids includes the silk of the cocoon.

Specialist The experiments with the specialist $M$. cinxia and its parasitoid $C$. melitaearum were undertaken in the field to allow for natural parasitism. Gregarious larval groups of $M$. cinxia were placed on intact potted plants in field locations where the parasitoid $C$. melitaearum is known to occur. Before putting the larvae on the plant, they were fed fresh leaves collected from $P$. lanceolata in the field. Groups of forty 3rd-instar caterpillars were placed onto single potted plants of 26 different genotypes of $P$. lanceolata (16 originating from the Netherlands, including the 13 genotypes used in the generalist experiments, and 10 originating from Åland, Finland). Five replicate plants of Dutch genotypes and three replicate plants of Finnish genotypes were used. Three plants were lost, so in total we used 107 plants and 4,280 caterpillars. Each pot was covered by a mesh cloth that prevented the caterpillars from escaping, but which allowed C. melitaearum to enter. Caterpillars were left in the field for 3 weeks, during which time their host plant was replaced with the same genotype if it was defoliated. After 3 weeks, all caterpillars had molted to their 5th (diapause) instar. The 2,728 recovered caterpillars then were removed from the plants, and a random subsample of caterpillars from each plant $(1,501$ in total $)$ was placed in a separate plastic container in a root cellar in Aland, where the larvae spent the winter in diapause. The following spring their diapause was broken and the larvae were fed fresh leaves from the same genotype on which 
they had fed the previous summer. Caterpillars were reared until pupation after the 7th larval instar, or larval parasitoid emergence. Post-diapause, the same parameters were measured as in the experiment with the generalists, except that larval development time was determined as the number of days between the breaking of diapauses, and emergence; adult longevity was not measured. Additionally we measured the survival of the larvae until diapause, and the number that survived overwintering. Because the hosts were parasitized naturally, rather than under visual observation in the laboratory, only a small fraction of the larvae was found to be parasitized (the natural rate of parasitism is low) (van Nouhuys and Punju, 2010). This approach allowed us to compare both the performance parameters and the rate of parasitism of larvae on the different genotypes of $P$. lanceolata.

\section{Chemical Analyses}

Collection of Leaf Material In the experiments with generalist herbivores and parasitoids, one mixed leaf sample per genotype was collected at three 4 weeks intervals, for analysis of leaf IG concentrations. The first two time points were during the growth period of the larvae. IG estimates from these two time points were averaged per genotype and used in tests of associations with insect performance parameters. Measurements from the third time point were used only to check for consistency of genotype differences over a longer time period. Each leaf sample consisted of the young and intermediate-aged leaves of at least 5 plants of the same genotype, as in the feeding trials. For the experiments with the specialist herbivore and parasitoid, leaves were sampled both pre- and postdiapause. From each plant, the 3rd and 4th fully grown leaf was collected before putting the pre-diapause caterpillars on them in the field. When a plant was completely defoliated and replaced by another of the same genotype, we also took the 3rd and 4th fully grown leaf from the second plant, and averaged their IG levels. Concentrations then were averaged per genotype and used in analyses of parasitism and survival until the breaking of diapause. After diapause, we took two subsamples of the leaves that were fed to the caterpillars per genotype, one early and one late during the remaining ca. 6 weeks development time of $M$. cinxia. The averages of these concentrations per genotype were then used to test for associations with post-diapause performance parameters.

Leaf IG Analysis These methods follow Marak et al. (2003). In brief, all leaves were freeze dried and ground to a fine powder with a ball mill (Retsch, type MM 301, Retsch GmbH and Co., Haan, Germany). Finely ground dry material from the leaves $(25 \mathrm{mg})$ was extracted in $10 \mathrm{ml}$ of
$70 \% \mathrm{MeOH}$ and was shaken overnight $\left(15^{\circ} \mathrm{C} / 100 \mathrm{RPM}\right)$. The crude extract was filtered through Whatman \#4 filter paper and the filtrate was diluted ten times with Milli-Q water. Concentrations of the IGs aucubin and catalpol were analyzed by HPLC using a Bio-Lc (Dionex, Sunnyvale, USA) equipped with a GP40 gradient pump, a Carbopac PA 1 guard $(4 \times 50 \mathrm{~mm})$ and analytical column $(4 \times 250 \mathrm{~mm})$, and an ED40 electrochemical detector for pulsed amperimetric detection (PAD). $\mathrm{NaOH}$ $(1 \mathrm{M})$ and Milli-Q water were used as eluents $(10: 90 \%$, $1 \mathrm{ml} / \mathrm{min}$ ). Retention times were $3.25 \mathrm{~min}$ and $4.40 \mathrm{~min}$ for aucubin and catalpol, respectively. Concentrations were analyzed using Chromeleon version 6.60 (Dionex Corp., Sunneyval, USA). A standard concentration series of aucubin and catalpol of $0.25,0.5,1.0,2.0,4.0$ and $8.0 \mathrm{ppm}$ was used for calibration.

\section{Statistical Analysis}

For the 13 plant genotypes that were included in both the generalist and specialist performance trials, we used ANOVA to analyze differences in IG between plant genotypes, between experiments (greenhouse-grown plants for generalists, field-grown plants for specialists), and their interaction. IG values were square-root transformed to meet assumptions of normality. In addition we used ANOVA to test whether there were differences in leaf IG concentrations between Dutch (artificially selected) and Finnish (collected from the wild) genotypes among the field grown plants.

Pearson correlations were used to test for associations between mean values for development parameters of the insects on the different plant genotypes and the mean IG concentration of those genotypes. The latter were based on the leaf samples collected during the corresponding experiment (greenhouse, field pre-diapause, or field post-diapause). For the generalist species, we analyzed larval and pupal development time, pupal and adult weight, and adult longevity. For the specialist,s the last two parameters were not measured. In addition, logistic regression was used to test whether mean larval and pupal survival on plant genotypes was affected by mean genotype IG concentration and whether parasitism of $M$. cinxia larvae by $C$. melitaearum was affected by mean genotype IG concentration. Since Dutch and Finnish genotypes appeared to differ in their IG profiles (catalpol and catalpol-to-total IG ratio, see results), we used ANCOVA to test whether genotype mean performance of specialists differed between genotypes from Finnish and Dutch origin, and whether effects of genotype origin were still significant if genotype mean catalpol or the ratio of catalpol to the total IG concentration [catalpol/ (aucubin+catalpol)] were included as a covariate. All 
statistical analyses were performed using SPSS for Windows Release 16.0.2.

\section{Results}

\section{Iridoid Glycoside Variation Among Plant Genotypes}

Genotype mean leaf IG concentrations of the 13 Dutch genotypes that were included in all performance studies varied circa six-fold, ranging from $1.28 \pm 0.21$ to $7.35 \pm 0.90$ (\% leaf dry weight \pm SE). The differences in leaf IG concentration among this set of genotypes were highly significant $(F[12,102]=11.03, P<0.001)$. The same was true for the constituent components aucubin $(F[12,102]=10.61$, $P<0.001)$ and catalpol $(F[12,102]=15.47, P<0.001)$ that showed ranges of among-genotype variation similar to those observed for total IG concentration. IG concentrations were lower in the greenhouse-grown plants (generalist performance study, Fig. 1a, ranging from $0.83 \pm 0.09$ to $6.41 \pm 1.02) \quad(F[1,102]=13.16, P<0.001)$ than in field-grown plants (specialist performance study, Fig. 1b, ranging from $1.47 \pm 0.26$ to $8.63 \pm 0.26$ ), but the ranking of the genotypes was maintained under both conditions (interaction $F[12,102]=1.10, P=0.36$ ). Mean leaf IG concentrations of the additional genotypes used in the specialist performance study all fell within the range of the 13 genotypes that were shared between the experiments.

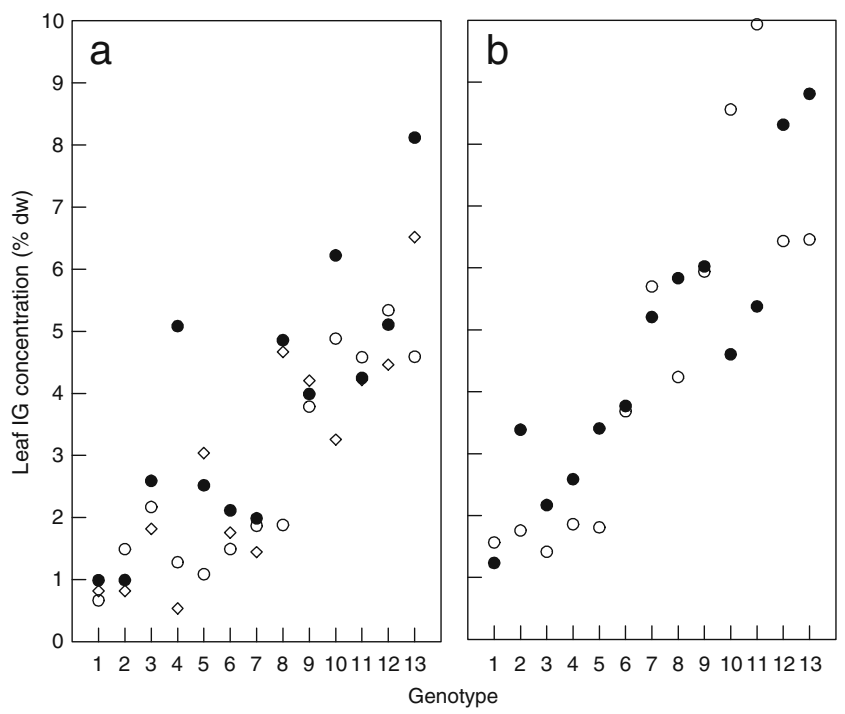

Fig. 1 Within- and between genotype variation in leaf iridoid glycoside (IG) concentrations in 13 Plantago lanceolata genotypes, ranked according to increasing genotype mean IG. (a) IG values from mixed leaf samples of each genotype taken at 4-wk intervals, two times during (circles) and one time after (diamond) the generalist feeding trials. (b) Mean values per genotype from samples taken before (open circles) and after diapause of specialists (closed circles), 10 months later
The mean IG values of the Finnish genotypes did not differ from the Dutch ones $(F[1,24]=0.24, P=0.63)$, but they contained more catalpol $(2.01 \pm 0.28$ vs. $1.09 \pm 0.28$, $F[1,24]=9.82, P=0.004)$, resulting in a higher contribution of catalpol to the total IG level in Finnish $(41.9 \%)$ than in the Dutch genotypes (31.7\%). Since variation in IG concentrations between genotypes was large compared to the temporal variation within genotypes at the scale of weeks (Fig. 1a) or even months (Fig. 1b), and since the ranking of genotypes with respect to their leaf IG concentrations was fairly consistent over time (Fig. 1a and b), we are confident that even though we did not intensively sample IGs during larval development, the genotype mean IG values that we used provide a reasonable estimate of differences in IG levels experienced by the insects during the experiment.

Effects of Iridoid Glycosides on Specialist and Generalist Herbivores

Generalists Larvae of the generalist herbivore C. chalcites developed slowly on plant genotypes with high IG concentrations (Table 1). For instance, an increase in the IG concentration from $1 \%$ to $6 \%$, the range spanned by the genotypes, caused a $20.0 \%$ (4.2 day) delay in larval development time (Fig. 2a). Development of the other generalist herbivore, S. exigua, also was slower on genotypes with higher IG concentrations, but in this species it was the pupal development that was delayed (Table 1). An increase in the average IG concentration from 1\% to $6 \%$ of leaf dry weight caused a 9.9\% (0.82 day) delay in pupal development (Fig. 2b). Adult longevity of $S$. exigua also was negatively affected by high leaf IG concentrations in its diet (Fig. 3a; $r=-0.642, P=0.03$ ). An increase in IG concentration from $1 \%$ to $6 \%$ of leaf dry weight reduced longevity by $59 \%$ (5.5 days). Adult longevity of the other generalist herbivore, $C$. chalcites, was independent of the concentration of IG in its diet $(r=-0.102, P=0.77)$. Pupal weight, pupal survival, and adult weight of the generalist herbivores were unaffected by the leaf IG concentrations in their diet. This does not mean that these parameters were not affected by host plant genotype. For instance, pupal mass was strongly affected by host plant genotype in both $C$. chalcites $(F[10,88]=12.81, P<0.001)$ and $S$. exigua $(F[12,90]=3.94, P<0.001)$, but apparently these effects were not mediated by differences in the concentrations of IGs in these plant genotypes.

Specialist Roughly half (51.6\%) of the caterpillars of the specialist $M$. cinxia from the 26 genotypes in the field and that had been randomly selected for further study survived diapause over winter. This is on par with the natural rate of overwintering survival (van Nouhuys et al., 2003). Their 
Table 1 Correlations between mean leaf concentrations of iridoid glycosides and mean performance (larval development time, cocoon weight and pupal development time) of insect herbivores and their parasitoids on genotypes of Plantago lanceolata

$N=$ Number of $P$. lanceolata genotypes included in the analysis $* P<0.10 ; * * P<0.05$

\begin{tabular}{|c|c|c|c|c|c|c|}
\hline Herbivore & Parasitoid & $N$ & $\begin{array}{l}\text { Larval development } \\
\text { time }\end{array}$ & $\begin{array}{l}\text { Cocoon } \\
\text { weight }\end{array}$ & $N$ & $\begin{array}{l}\text { Pupal development } \\
\text { time }\end{array}$ \\
\hline \multirow[t]{3}{*}{ Chrysodeixis chalcites } & & 11 & $+0.684 * *$ & -0.434 & 11 & -0.444 \\
\hline & Cotesia marginiventris & 10 & $-0.643 * *$ & $+0.568 *$ & 7 & -0.500 \\
\hline & Hyposoter didymator & 11 & -0.050 & -0.000 & 11 & +0.219 \\
\hline \multirow[t]{3}{*}{ Spodoptera exigua } & & 13 & -0.035 & -0.308 & 11 & $+0.726^{* *}$ \\
\hline & Cotesia marginiventris & 13 & -0.232 & +0.214 & 13 & $-0.590 * *$ \\
\hline & Hyposoter didymator & 7 & -0.466 & -0.286 & 4 & +0.093 \\
\hline \multirow[t]{2}{*}{ Melitaea cinxia } & & 21 & +0.220 & -0.047 & 11 & -0.263 \\
\hline & Cotesia melitaearum & 8 & +0.198 & -0.082 & 6 & +0.133 \\
\hline
\end{tabular}

probability of survival was significantly lower when they originated from plant genotypes with high levels of catalpol before diapause (Fig. 4A, logistic regression, Wald $\left.\chi^{2}[1]=8.23, P=0.004\right)$. An increase in leaf catalpol concentration from $0.5 \%$ to $3.0 \%$, the range encompassed by the genotypes, was associated with a decrease in survival from $59 \%$ to $37 \%$. Survival of diapausing larvae was lower when they had been raised on Finnish (Fig. 4a, open symbols) than on Dutch genotypes (Fig. 4a, closed symbols) before diapause (Wald $\chi^{2}[1]=4.50, P=0.03$ ). This difference could be explained by the higher catalpol concentrations in Finnish genotypes: effect of genotype origin (Finnish vs. Dutch) was no longer significant in a multiple logistic regression in which both genotype origin and genotype mean catalpol concentration were entered, whereas the latter effect was still significant. None of the post-diapause developmental parameters of $M$. cinxia were significantly associated with post-diapause levels of IGs in the herbivore's diet (Table 1), except for a faster development of post-diapause larvae on genotypes with a higher catalpol-to-total IG ratio ( $r=-0.504, P=0.02)$. Consequently, post-diapause larval development of $M$. cinxia was

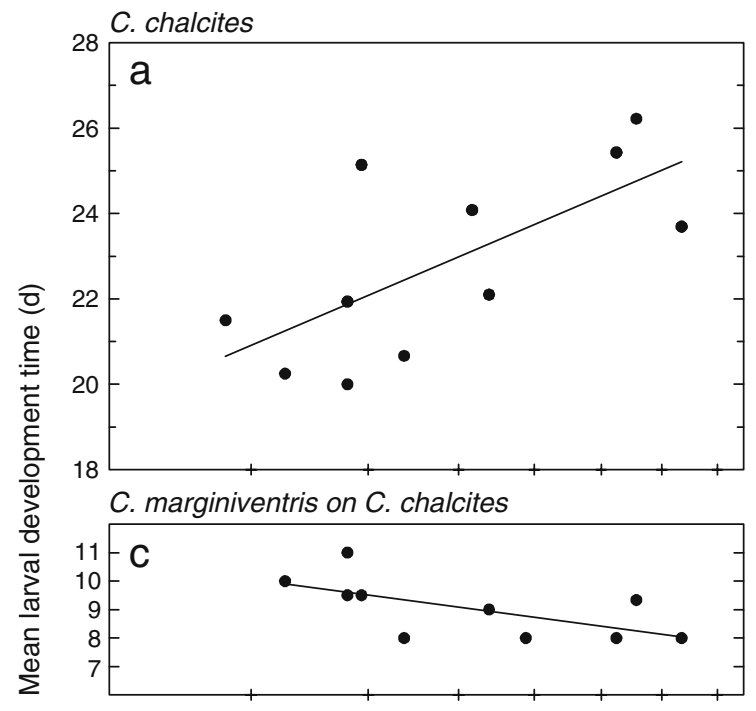

S. exigua
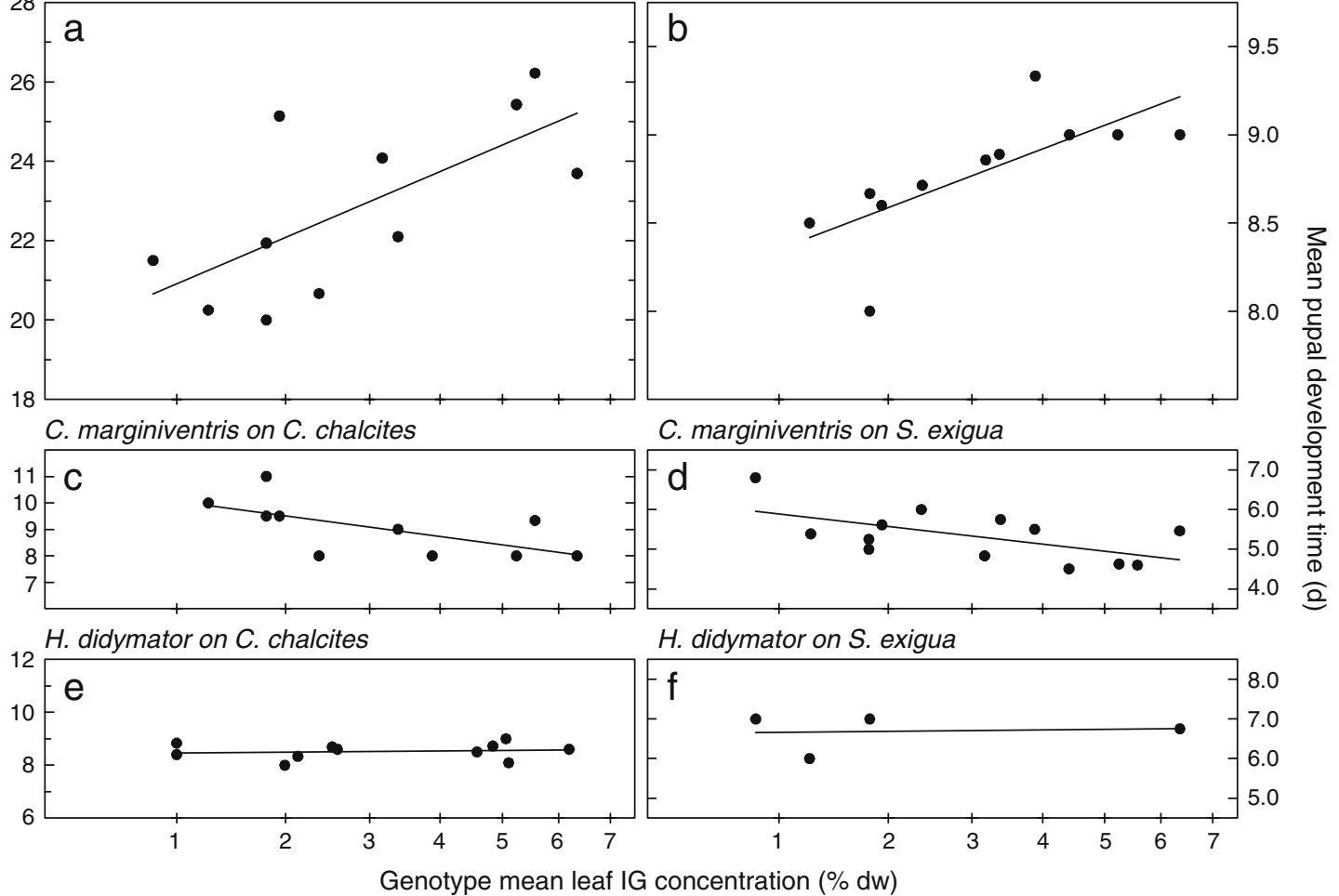

H. didymator on S. exigua

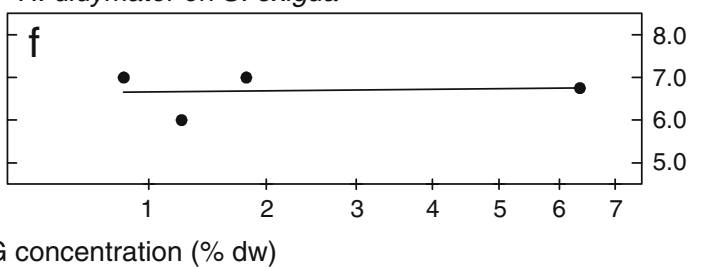

Fig. 2 Development time of generalist herbivores and parasitoids as a function of genotype mean leaf iridoid glycoside (IG) concentration in the food plant Plantago lanceolata. Left panels: mean larval development time of Chrysodeixis chalcites (a) and its parasitoids Cotesia marginiventris (c) and Hyposoter didymator (e). Right panels: mean pupal development time of Spodoptera exigua (b) and the same two parasitoids (d, f). Note the square-root scale of the $\mathrm{X}$-axis 


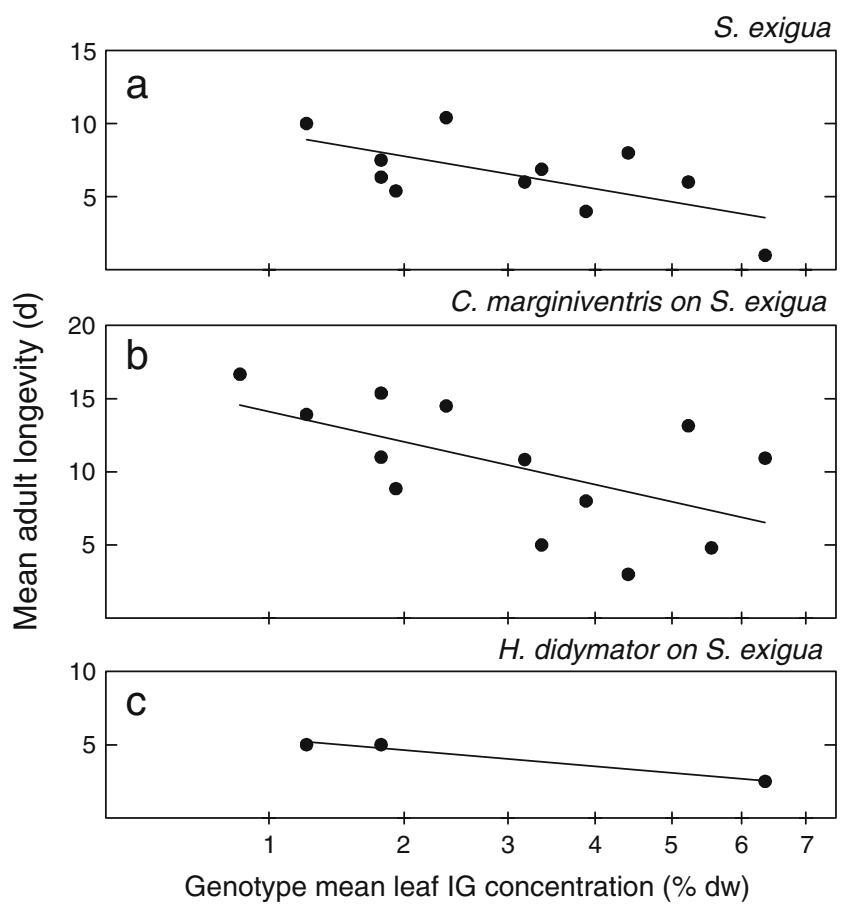

Fig. 3 Mean adult longevity of the generalist herbivore Spodoptera exigua (a) and its parasitoids Cotesia marginiventris (b) and Hyposoter didymator (c) as a function of genotype mean leaf iridoid glycoside (IG) concentration in the food plant Plantago lanceolata. Note the square-root scale of the $\mathrm{X}$-axis

faster on Finnish genotypes, that on average had a high catalpol-to-total IG ratio, than on Dutch genotypes (46.0 \pm 1.8 vs. $38.9 \pm 1.9$ days, $F[1,20]=5.50, P=0.03$ ).

Additional analyses confirmed that the differences in post-diapause larval development time on Finnish vs. Dutch genotypes could be partly explained by differences in their IG profiles: when catalpol-to-total IG ratio was entered as a covariate in analyses of genotype origin (Finnish vs. Dutch) on larval development time, the significant effect of catalpolto-total IG concentration remained $(F[1,19]=6.16, P=0.02)$, whereas genotype origin (Finnish vs. Dutch) could explain only little additional variation $(F[1,19]=3.36$, $P=0.08$ ). This was not the case for post-diapause survival of $M$. cinxia larvae on Finnish vs. Dutch genotypes. Postdiapause survival until pupation was three times higher on Finnish than on Dutch genotypes (15.6 vs. 5.0\%, logistic regression, Wald $\left.\chi^{2}[1]=9.10, P=0.003\right)$, and was independent of their IG profiles $(P>0.6)$. Moreover, the probability of pupal survival to adulthood was four times higher on Finnish than on Dutch genotypes (56.0 vs. $12.9 \%$, logistic regression, Wald $\left.\chi^{2}[1]=17.39, P<0.001\right)$, also independent of their IG profiles $(P>0.3)$. The greater survival to adulthood by Finnish pupae was not mediated by pupal mass, which did not differ between individuals raised on Finnish vs. Dutch genotypes (148 vs. $140 \mathrm{mg}$, $F[1,20]=0.76, P=0.39)$.

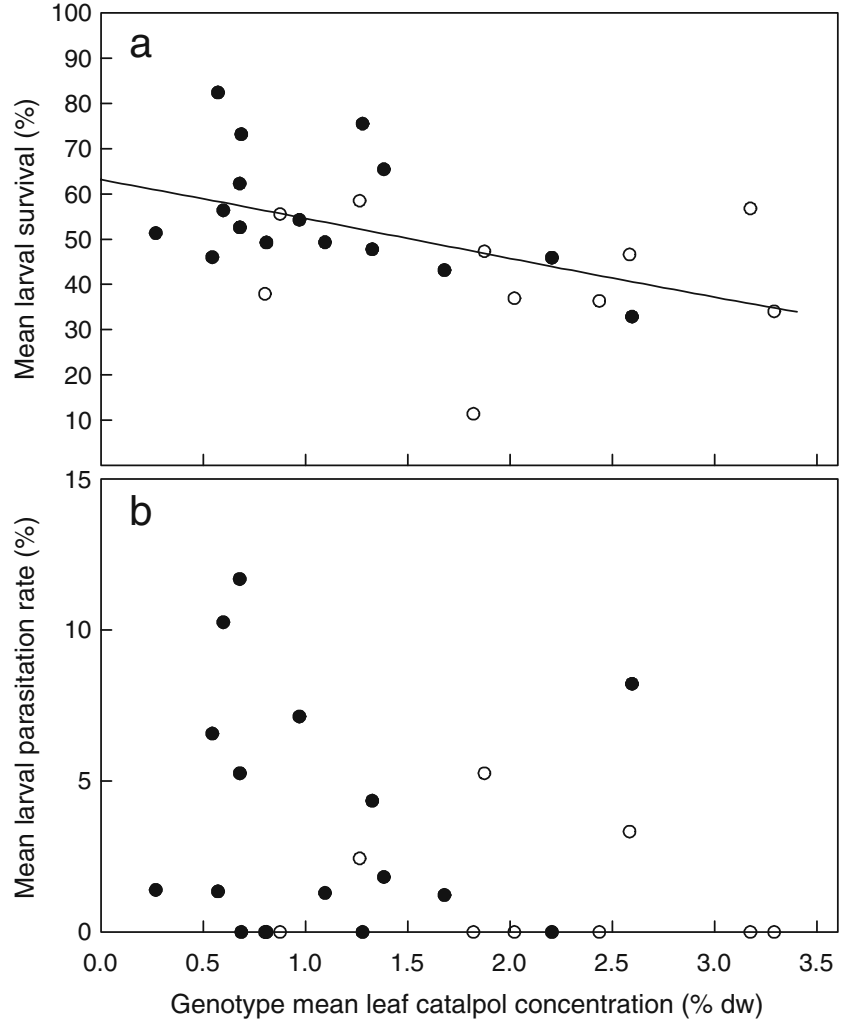

Fig. 4 (a) Mean survival of diapausing larvae of the specialist herbivore Melitaea cinxia and (b) Mean parasitism rate of $M$. cinxia by Cotesia melitaearum as a function of genotype mean leaf catalpol concentration in the food plant Plantago lanceolata. Closed circles: Dutch plant genotypes; open circles: Finnish plant genotypes. Lines are fitted values from logistic regressions based on data from all genotypes

Effects of Iridoid Glycosides on the Generalist and Specialist Parasitoids

Generalists Overall, associations between plant IGs and development time of the generalist parasitoids were not concordant with those observed for their hosts. Larvae of the parasitoid $C$. marginiventris developed faster on $C$. chalcites (Fig. 2c), and their pupae developed faster on $S$. exigua (Fig. 2d) when these herbivores had been feeding on genotypes with high IG concentrations (Table 1). An increase in IG concentration from $1 \%$ to $6 \%$ of leaf dry weight was accompanied by advancement in larval and pupal development by $19 \%$ on these hosts, (1.9 and 1.1 days, respectively). Effects on longevity were more concordant between hosts and parasitoids. In accordance with its host $S$. exigua, adult longevity of $C$. marginiventris decreased with higher IG concentrations in the diet of this host (Fig. 3b; $r=-0.580, P=0.04$ ). An increase in IG concentration from $1 \%$ to $6 \%$ of leaf dry weight reduced longevity by $51 \%$ ( 7.2 days). Adult longevity of the other generalist parasitoid, $H$. didymator, also on average decreased 
with increasing IG concentration in the diet of its host $S$. exigua (Fig. 3C), but too few parasitoids on this host survived until adulthood to allow meaningful tests of significance. None of the other developmental parameters of $H$. didymator were significantly affected by IG concentration (Table 1, Fig. 2e,f).

Some of the developmental parameters were not associated with the total concentration of IGs in the plant genotypes on which hosts were raised but only with the specific compounds aucubin or catalpol. Survival of C. marginiventris pupae to adulthood decreased with the concentration of catalpol in the plant genotypes fed to its host on $S$. exigua (logistic regression, Wald $\chi^{2}[1]=5.60, P=0.02$ ). An increase in catalpol from $0.3 \%$ to $1.8 \%$ of leaf dry weight, the range encompassed by the genotypes, more than doubled the mortality of $C$. marginiventris pupae, from $14.5 \%$ to $31.8 \%$. No such effects were observed for aucubin (Wald $\chi^{2}[1]=0.41, P=0.52$ ). Pupal mass of $H$. didymator decreased with increasing ratio of catalpol-to-total IG in the plant genotypes fed to its host $C$. chalcites $(r=-0.827$, $P=0.002$ ) on $C$. chalcites. The reduction in pupal mass of this parasitoid observed on the other host, S. exigua, was not statistically significant $(r=-0.766, P=0.076)$.

Specialist On 15 of the 26 plant genotypes that were placed into natural host populations in the field, at least one $M$. cinxia caterpillar was parasitized by $C$. melitaearum. In total, $3.2 \%$ of the caterpillars were parasitized, with a mean secondary brood size of 2.1 parasitoids per parasitized caterpillar. This is a normal rate of parasitism of pre-diapause $M$. cinxia larvae by $C$. melitaearum in Åland (Lei et al., 1997). The parasitism rate was not significantly affected by the level of IGs in the plant genotypes that hosts had been feeding on before diapause. The parasitism rate on average decreased with the concentration of catalpol in the genotypes on which $M$. cinxia had been raised (Fig. 4b), but this pattern was not statistically significant (logistic regression, Wald $\chi^{2}[1]=1.70$, $P=0.19)$. Accordingly, the parasitism rate was on average lower on Finnish (1.05\%) genotypes (that had relatively high catalpol concentrations) than on Dutch genotypes $(3.93 \%)$, but this difference was also not statistically significant (logistic regression, Wald $\chi^{2}[1]=2.81, P=0.09$ ). None of the post-diapause developmental parameters of $C$. melitaearum were significantly associated with post-diapause levels of IGs in the herbivore's diet.

\section{Discussion}

Our study supports findings from earlier studies showing that the development of generalist and specialist insect herbivores and their parasitoids is often strongly associated with intra- or inter-specific variation in concentrations of secondary plant compounds (e.g., Barbosa, 1988; Barbosa et al., 1991; Adler et al., 1995; Harvey et al., 2005, 2007a; reviewed by Ode, 2006). Our results show that the strength and direction of such associations may not only differ between generalists and specialists but also between trophic levels: responses in development time to plant allelochemical variation differed between herbivores and their associated parasitoids.

Herbivores Larval development of the generalist herbivore C. chalcites and pupal development of the generalist herbivore $S$. exigua were significantly delayed on plant genotypes with high levels of IGs. This increases their development time, potentially decreasing the intrinsic rate of increase at the population level. It also may increase their window of susceptibility to natural enemies, as in the 'slow-growth high-mortality' hypothesis (Clancy and Price, 1987), which states that herbivores are potentially more vulnerable to larval and pupal parasitoids, pathogens, and predators when they feed on host plants with high levels of allelochemicals that extend their development time. Our results confirm those of earlier studies (Biere et al., 2004) showing that development time of $S$. exigua is prolonged on $P$. lanceolata genotypes selected for high leaf IG concentrations, but the results contrast with studies of Harvey et al. (2005) in which S. exigua only suffered reduced pupal weight on high-IG genotypes. Apparently, the stage and specific parameters at which negative associations between host IG and development are expressed can vary even within a single system. In the current experiment, feeding on high-IG genotypes was not associated with reduced pupal or adult weight of the generalist herbivores, traits, which are generally correlated with fecundity (Leather, 1988; Klingenberg and Spence, 1997; Saastamoinen, 2007). Only longevity of adult $S$. exigua, another trait that may be associated with fecundity, was reduced on high-IG plant genotypes. Interestingly, both $C$. chalcites and $S$. exigua showed large variation in pupal and adult mass on different plant genotypes, which was unrelated to differences in IGs among these genotypes. Apparently, traits other than IGs varied among these genotypes, and played a role in determining pupal and adult mass of the generalist insect herbivores.

With respect to associations between IGs and development time, the results for the specialist herbivore $M$. cinxia contrast with those for the two generalist herbivores. Whereas development time of the generalists was delayed on plant genotypes with high total leaf IG concentrations, that of $M$. cinxia was not. Development time of this specialist only responded to variation in the profile, not the total concentration, of leaf IGs; larvae developed more quickly on genotypes with high catalpol-to-total IG ratios. 
Contrasts between specialist and generalist herbivores in their development time responses to the total leaf IG concentration in their hosts have been observed previously. Harvey et al. (2005) found that M. cinxia caterpillars developed faster on high-IG than on low-IG genotypes (see also Saastamoinen et al., 2007), whereas development time of the generalist $S$. exigua was unaffected by IG variation among genotypes. It is unclear why in our study the development time of this generalist was longer on high-IG genotypes than in the study of Harvey et al. (2005). One reason might be that we used a wider range of IG variation among genotype means $(0.8-6.4 \% \mathrm{dw})$ than was encompassed by the two lines used by Harvey et al. (2005) (0.6 vs. $3.0 \% \mathrm{dw})$. However, what these studies have in common is the observation that on high-IG plants the development of the specialist is either less delayed (our study), or even more advanced (Harvey et al., 2005) compared to that of generalist herbivores. Similar observations have been made for other allelochemicals. For instance, pyrrolizidine alkaloids (PAs) commonly impact generalist herbivores, even though the strength of their effect may differ strongly among generalist species (Macel et al., 2005), but not specialists (Macel et al., 2002). These results support the general notion that specialized mono- or oligophagous herbivores are often better able to cope with allelochemicals in the host on which they are specialized than polyphagous herbivores, at least in terms of their development rate.

Our results correspond well with results from artificial diet studies with IGs (e.g., Bowers and Puttick, 1988; Puttick and Bowers, 1988; Mallampalli et al., 1996). These studies have shown that addition of aucubin and catalpol to artificial diet strongly reduces larval growth rates, at least during the early stages of growth, of the generalist caterpillars Lymantria dispar and Spodoptera eridania, but can increase larval growth rate of the specialist Junonia coenia (Bowers and Puttick, 1988), even though this specialist generally experiences slightly lower feeding efficiency on high- compared to low-IG artificial diets (Camara, 1997a; Smilanich et al., 2009).

Artificial diet studies provide more direct evidence for causal links between IGs and insect development than our correlative studies based on plant genotypes that differ in IGs, because traits that covary with IGs in the plant might affect insect performance as well. We tried to minimize such associations by using a core set of genotypes derived from artificial selection lines that had been subjected to four generations of selection for low and high leaf IG concentrations (Marak et al., 2000). During selection, pre-existing associations are generally broken up, unless they are caused by pleiotropy or very close linkage. Indeed, analysis of a subset of plants from the 13 genotypes that were used in all experiments of the current study revealed that among-genotype correlations between concentrations of leaf IGs and concentrations of leaf nutrients, which are also important determinants of development of insect herbivores, were non-significant (Pearson correlation coefficients between IGs and $\mathrm{N}: r=+0.31$, $P=0.31$; P: $r=+0.26, P=0.39$; K: $r=+0.34, P=0.26$, J. H. Reudler, unpublished results). This suggests that our results probably have not been confounded with effects of co-varying levels of primary metabolites.

The large differences in post-diapause development of the specialist herbivore $M$. cinxia on the Finnish and Dutch $P$. lanceolata genotypes however, does illustrate the importance of other plant traits, in addition to IGs, in governing the interactions between P. lanceolata and its insect herbivores. Developmental success of $M$. cinxia was much higher on their local, Finnish, genotypes than on the Dutch genotypes: they developed faster and showed higher larval and pupal survival on the local genotypes. Finnish genotypes had consistently higher levels of catalpol than Dutch genotypes, a difference that was reflected in higher ratios of catalpol to the total amount of IGs. To our surprise, only the faster development of post-diapause $M$. cinxia larvae on Finnish than on Dutch genotypes could be (partly) explained by the differences in their IG profiles. Differences in IG profiles between Finnish and Dutch genotypes could not explain the large differences in post-diapause larval and pupal survival of M. cinxia on these genotypes. This suggests that M. cinxia has adapted to feeding on its local hosts at least partly in response to attributes other than their IG chemistry. Adaptation of insect herbivores to their local host plants is common, though not ubiquitous (Kaltz and Shykoff, 1998; Ballabeni et al., 2003; Greischar and Koskella, 2007), and the traits that underlie local adaptation may involve many aspects other than those involved in allelochemical-based interactions (e.g., Zovi et al., 2008).

Parasitoids The performance of the two generalist parasitoids on the generalist herbivores was associated strongly with the leaf IG concentrations in the plant genotypes on which these hosts were raised. In contrast to earlier studies (Mallampalli et al., 1996; Harvey et al., 2005), the magnitude and even direction of the correlations between IGs and performance of the parasitoids did not follow that of the hosts. Notably, whereas both of the generalist herbivores developed slowly on plant genotypes with high IG concentrations, the parasitoid C. marginiventris actually developed faster on both host species when they were reared on high-IG genotypes. The faster development of $C$. marginiventris on hosts that suffered from feeding on high-IG plants is surprising, since negative effects of the ingestion of toxic allelochemicals on the performance and quality of herbivores often have been observed to vertically transfer to higher trophic levels (Campbell and Duffey, 1979; Barbosa et al., 
1986, 1991; Harvey et al., 2007a; Lampert et al., 2008), especially in interactions where hosts sequester toxic allelochemicals (part of the "nasty host" hypothesis; Gauld et al., 1992, Lampert et al., 2010). One possible explanation for the faster growth of $C$. marginiventris on these hosts is that higher levels of allelochemicals in the host diet weaken the host immune system, as observed for $J$. coenia feeding on high-IG artificial diets (Smilanich et al., 2009), thus allowing the developing parasitoids to reallocate metabolic energy from immunosuppression to development (Kraaijeveld and Godfray, 1997; Ojala et al., 2005), the "immunocompromized host" effect. This hypothesis remains to be confirmed for the species studied here. Associations between adult longevity and host IGs were more concordant between herbivores and parasitoids. Longevity of adult S. exigua was significantly reduced on high-IG genotypes and so was that of $C$. marginiventris, when raised on this host. Similarly, longevity of both adult $C$. chalcites and its parasitoids was not affected by leaf IG concentration in the host's diet.

The effect of IGs in the diet of the generalist herbivores on the performance of their parasitoids strongly differed between the two parasitoid species. A high concentration of IGs in the diet of both host species resulted in faster development of $C$. marginiventris, despite slower development of its hosts, but did not affect the development of $H$. didymator. This illustrates that even when we consider interactions with a specific group of parasitoids, such as generalist endo-koinobionts, effects of IGs in the diet of an herbivore on interactions with its parasitoids cannot be generalized. Part of the difference between parasitoid species may be due to their different feeding modes. Cotesia marginiventris is a haemolymph feeder whereas $H$. didymator feeds on tissue. Haemolymph feeders may be less constrained by host growth rate than tissue feeders that have to consume their host before being able to emerge (Harvey et al., 2000; Harvey and Strand, 2002). Previous studies similarly found that the related tissue feeder Hyposoter horticola more closely followed developmental responses of the host $M$. cinxia to IG variation than the haemolymph feeder C. melitaearum (Harvey et al., 2005).

In contrast to the generalist parasitoids, development of the specialist parasitoid $C$. melitaearum did not vary with the IG levels in the plant genotypes on which its host $M$. cinxia was reared, in agreement with the results of Harvey et al. (2005). Nieminen et al. (2003) found that in natural populations, the rate of parasitism of $M$. cinxia by $C$. melitaearum decreased with the concentration of catalpol in the P. lanceolata. Although we found the same trend in our experiment, the decrease was not statistically significant, perhaps due to small sample size. Effects of host plant IGs on parasitism rates could result from two different processes. First, adult parasitoids may avoid ovipositing into host larvae feeding on high-IG plants. Second, development of immature parasitoids may be less successful on hosts feeding on high IG plants. For instance, whereas field parasitism of the Catalpa sphinx moth (Ceratomia catalpa), a species that sequesters IGs (Bowers, 2003), by the parasitoid Cotesia congregata appears to be independent of caterpillar IG concentrations, survival of this parasitoid is slightly lower on high-IG caterpillars (Lampert et al., 2010). Melitaea cinxia also is known to sequester IGs (Suomi et al. 2001, 2003) and development of $C$. melitaearum larvae on high-IG caterpillars may be less successful if the negative effects due to the vertical transfer of these toxic allelochemicals (the "nasty host" effects) more than outweigh any positive effects due to decreased immunocompetence of the host (the "immunocompromized host" effect). Interestingly, in contrast to $J$. coenia, that is immunocompromized when feeding on high-IG diets (Smilanich et al., 2009), Laurentz (2010) found no evidence for a decreased immune function in $M$. cinxia. In fact, $M$. cinxia showed higher levels of encapsulation of artificial implants when reared on plants with high levels of catalpol.

In summary, we found that development time of the specialist herbivore was less negatively impacted by highIG genotypes than that of both of the generalists, supporting the idea that specialist herbivores are better adapted to allelochemicals in their hosts than are generalist herbivores. We also found that generalist parasitoids developed faster on hosts feeding on high-IG genotypes whereas the specialist parasitoid was not strongly impacted by the IG concentration in the diet of its host, which could reflect differences in the effects of IGs on immunocompetence on the different hosts that they parasitized. Our study, therefore, shows that associations between IG concentrations in $P$. lanceolata and development of its associated insect herbivores and parasitoids are species-specific.

Acknowledgements We thank N. Volkoff for providing the $H$. didymator cocoons, and $\mathrm{C}$. Faria for providing $C$. marginiventris cocoons. We thank Nåtö Biological Station and Ålands naturbruksskola for laboratory facilities. K. Fedrowitz and R. Kaartinen for laboratory assistance. This study was supported by a grant from the Earth and Life Science Foundation (ALW) of the Netherlands Organization for Scientific Research (NWO) and by the Academy of Finland Centre of Excellence Program grants numbers 20386 and 213457. Publication 5051 Netherlands Institute of Ecology (NIOOKNAW).

Open Access This article is distributed under the terms of the Creative Commons Attribution Noncommercial License which permits any noncommercial use, distribution, and reproduction in any medium, provided the original author(s) and source are credited.

\section{References}

AdLer, L. S., SchmitT, J., and Bowers, M. D. 1995. Genetic variation in defensive chemistry in Plantago lanceolata 
(Plantaginaceae) and its effect on the specialist herbivore Junonia coenia (Nymphalidae). Oecologia 101:75-85.

AgraWAL, A. A. 2000. Specificity of induced resistance in wild radish: causes and consequences for two specialist and two generalist caterpillars. Oikos 89: 493-500.

Ballabeni, P., GotThard, K., KaYUMBa, A., and Rahier, M. 2003. Local adaptation and ecological genetics of host-plant specialization in a leaf beetle. Oikos 101: 70-78.

Bar, D., Gerlings, D., and Rossler, Y. 1979. Bionomics of the principal natural enemies attacking Heliothis armigera in cotton fields in Israel. Environ. Entomol. 8: 468-474.

BARBOSA, P. 1988. Natural enemies and herbivore-plant interactions: influence of plant allelochemicals and host specificity, pp. 201229, in P. Barbosa and D. K. Letourneau (eds.). Novel Aspects of Insect-Plant Interactions. John Wiley and Sons, New York.

Barbosa, P., Saunders, J. A., Kemper, J., Trumbule, R., Olechno, J., and MARTINAT, P. 1986. Plant allelochemicals and insect parasitoids. Effects of nicotine on Cotesia congregata (Say) (Hymenoptera, Braconidae) and Hyposoter annulipes (Cresson) (Hymenoptera, Ichneumonidae). J. Chem. Ecol. 12: 1319-1328.

BArbosA, P., Gross, P., and KeMPER, J. 1991. Influence of plant allelochemicals on the tobacco hornworm and its parasitoid, Cotesia congregata. Ecology 72: 1567-1575.

BARTON, K. E. 2007. Early ontogenetic patterns in chemical defense in Plantago (Plantaginaceae): genetic variation and trade-offs. Am. J. Bot. 94: 56-66.

Biere, A., MaraK, H. B., and Van Damme, J. M. M. 2004. Plant chemical defense against herbivores and pathogens: generalized defense or trade-offs ? Oecologia 140: 430-441.

BOWERS, M. D. 1980. Unpalatability as a defense strategy of Euphydryas phaeton (Lepidoptera: Nymphalidae). Evolution 34: 586-600.

BOWERS, M. D. 1981. Unpalatability as a defense strategy of western checkerspot butterflies (Euphydryas, Nymphalidae). Evolution 35: $367-375$

BOWERS, M. D. 1984. Iridoid glycosides and host-plant specificity in larvae of the buckeye butterfly, Junonia coenia (Nymphalidae). J. Chem. Ecol. 10: 1567-1577.

BOWERS, M. D. 1991. Iridoid glycosides, pp. 297-325, in G. A. Rosenthal and M. R. Berenbaum (eds.). Herbivores: Their Interactions with Secondary Plant Metabolites. Academic Press, San Diego.

BOWERS, M. D. 2003. Hostplant suitability and defensive chemistry of the Catalpa sphinx, Ceratomia catalpae. J. Chem. Ecol. 29: 2359-2367.

Bowers, M. D., and Collinge, S. K. 1992. Fate of iridoid glycosides in different life stages of the buckeye, Junonia coenia (Lepidoptera, Nymphalidae). J. Chem. Ecol. 18: 817-831.

Bowers, M. D., and PUTTICK, G. M. 1988. Response of generalist and specialist insects to qualitative allelochemical variation. $J$. Chem. Ecol. 14: 319-334.

Bowers, M. D., and STAMP, N. E. 1992. Chemical variation within and between individuals of Plantago lanceolata (Plantaginaceae). J. Chem. Ecol. 18: 985-995.

Bowers, M. D., Collinge, S. K., Gamble, S. E., and Schmitt, J. 1992. Effects of genotype, habitat, and seasonal variation on iridoid glycoside content of Plantago lanceolata (Plantaginaceae) and the implications for insect herbivores. Oecologia 9: 201-207.

CAMARA, M. D. 1997a. Physiological mechanisms underlying the costs of chemical defence in Junonia coenia Hubner (Nymphalidae): a gravimetric and quantitative genetic analysis. Evol. Ecol. 11: 451-469.

CAmara, M. D. 1997b. Predator responses to sequestered plant toxins in buckeye caterpillars: are tritrophic interactions locally variable? $J$. Chem. Ecol. 23: 2093-2106.

CAmpbell, B. C., and Duffey, S. S. 1979. Tomatine and parasitic wasps: potential incompatibility of plant antibiosis with biological control. Science 205: 700-702.
Clancy, K. M., and PRICE, P. W. 1987. Rapid herbivore growth enhances enemy attack: sublethal plant defenses remain a paradox. Ecology 68: 736-738.

CoOper, S. M., and OWen-SMith, N. 1986. Effects of plant senescence on large mammalian herbivores. Oecologia 68: 446-455.

CoRnell, H. V., and HaWkins, B. A. 2003. Herbivore responses to plant secondary compounds: a test of phytochemical coevolution theory. Am. Nat. 161: 507-522.

Damtoft, S., Jensen, S. R., and Nielsen, B. J. 1983. The biosynthesis of iridoid glycosides from 8-epi-deoxyloganic acid. Biochemical Society Transactions 11: 593-594.

DARrow, K., and Bowers, M. D. 1997. Phenological and population variation in iridoid glycosides of Plantago lanceolata (Plantaginaceae). Biochem. Sys. Ecol. 25: 1-11.

DenNo, R. F., and MCCluRe, M. S. 1983. Variable Plants and Herbivores in Natural and Managed Systems. Academic Press, New York.

DUFFEY, S. S. 1980. Sequestration of plant natural products by insects. Annu. Rev. of Entomol. 25: 447-477.

Duffey, S. S., Bloem, K. A., and CAmpbell, B. C. 1986. Consequences of sequestration of plant natural products in plant-insect-parasitoid interactions, pp. 31-60, in D. J. Boethel and R. D. Eikenbary (eds.). Interactions of Plant Resistance and Parasitoids and Predators of Insects. Horwood, Chichester, UK.

EHRLICH, P. R., and RAVEN, P. H. 1964. Butterflies and plants: a study in coevolution. Evolution 18: 586-608.

ElziNGA, J. A. 2002. The rearing of the gregarious koinobiont endoparasitoid Microplitis tristis (Hymenoptera: Braconidae) on its natural host Hadena bicruris (Lepidoptera: Noctuidae). Proc. Sect. Exp. Appl. Entomol. Netherl. Entomol. Soc. (NEV) 13: 109-115.

FAJER, E. D., Bowers, M. D., and BAzZAZ, F. A. 1992. The effect of nutrients and enriched $\mathrm{CO} 2$ environments on production of carbon-based allelochemicals in Plantago: a test of the carbon/ nutrient balance hypothesis. Am. Nat. 140: 707-723.

Figueiredo, E., MexícA, A., Albajes, R., and SEKeroglu, E. 2000. Parasitoid complex associated with Lepidoptera on horticultural protected crops in the Oeste region of Portugal. IOBC WPRS Working Group "Integrated Control in Protected Crops, Mediterranean Climate". Bull. OILB SROP 23: 205-208.

FrAENKEL, G. S. 1959. The raison d'étre of secondary plant substances. The odd chemicals arose as a means of protecting plants from insects and now guide insects to food. Science 129: $1466-1470$.

Gauld, I. D., Gaston, K. J., and Janzen, D. H. 1992. Plant allelochemicals, tritrophic interactions and the anomalous diversity of tropical parasitoids - the nasty host hypothesis. Oikos 65: 353-357.

GODFRAY, H. C. J. 1994. Parasitoids: Behavioural and Evolutionary Ecology. Princeton University Press, Princeton, NJ.

Goodey, B. 1991. Chrysodeixis chalcites (Esper, 1789) (Lep.: Noctuidae): observations on the life cycle in captivity. Entomol. Rec. 103:111-118.

Greischar, M. A., and Koskella, B. 2007. A synthesis of experimental work on parasite local adaptation. Ecol. Lett. 10: 418-434.

Gunasena, G. H., Vinson, S. B., and Williams, H. J. 1990. Effects of nicotine on growth, development, and survival of the tobacco budworm (Lepidoptera, Noctuidae) and the parasitoid Campoletis sonorensis (Hymenoptera, Ichneumonidae). J. Ecol. Entomol. 83: $1777-1782$.

HARVEY, J. A., and StRAND, M. R. 2002. The developmental strategies of endoparasitoid wasps vary with host feeding ecology. Ecology 83: 2439-2451.

HarVEY, J. A., KADASh, K., and Strand, M. R. 2000. Differences in larval feeding behavior correlate with altered developmental 
strategies in two parasitic wasps: implications for the size-fitness hypothesis. Oikos 88: 621-629.

Harvey, J. A., Van NouhuYs, S., and Biere, A. 2005. Effects of quantitative variation in allelochemicals in Plantago lanceolata on development of a generalist and a specialist herbivore and their endoparasitoids. J. Chem. Ecol. 31: 287-302.

Harvey, J. A., Gols, R., WagenaAr, R., and Bezemer, T. M. 2007a. Development of an insect herbivore and its pupal parasitoid reflect differences in direct plant defense. J. Chem. Ecol. 33: $1556-1569$.

Harvey, J. A., Van Dam, N. M., Witjes, L. M. A., Soler, R., and GoLS, R. 2007b. Effects of dietary nicotine on the development of an herbivore, its parasitoid and secondary hyperparasitoid over four trophic levels. Ecol. Entomol. 32: 15-23.

INGRAM, W. R. 1981. The parasitoids of Spodoptera littoralis (Lep.: Noctuidae) and their role in population control in Cyprus. Entomophaga 26: 23-37.

Johnson, K. S. 1999. Comparative detoxification of plant (Magnolia virginiana) allelochemicals by generalist and specialist saturniid silkmoths. J. Chem. Ecol. 25: 253-269.

KALTZ, O., and SHYKOFF, J. A. 1998. Local adaptation in host-parasite systems. Heredity 81: 361-370.

KANKARE, M., and SHAW, M. R. 2004. Molecular phylogeny of Cotesia (Hymenoptera: Braconidae: Microgastrinae) parasitoids associated with checkerspot butterflies. Mol. Phylogenet. Evol. 32: $207-220$

Kankare, M., Van NouhuYs, S., and Hanski, I. 2005. Genetic divergence among host-specific cryptic species in Cotesia melitaearum aggregate (Hymenoptera: Braconidae), parasitoids of checkerspot butterflies. Ann. Entomol. Soc. Am. 98: 382-394.

KLingENBERG, C. P., and SPENCE, J. R. 1997. On the role of body size for life-history evolution. Ecol. Entomol. 22: 55-68.

KraAiJeVeld, A. R., and Godfray, H. C. J. 1997. Trade-off between parasitoid resistance and larval competitive ability in Drosophila melanogaster. Nature 389: 278-280.

Krombein, K. V., HuRD, P. D., SMITH, D. R., and BuRKs, B. D. 1979. Catalogue of Hymenoptera of America North of Mexico. Smithsonian Institute Press, Washington D.C.

KuUSSAARI, M., VAN NOUHUYS, S., HellmanN, J., and Singer, M. 2004. Larval biology of checkerspots, pp. 138-160, in P. R. EHRLICH and I. Haski, (eds.). On the Wings of Checkerspots: a Model System for Population Biology. University Press, Oxford.

LAMPERT, E. C., and BowERs, M. D. 2010. Host plant species affects the quality of the generalist Trichoplusia ni as a host for the polyembryonic parasitoid Copidosoma floridanum. Entomol. Exp. Appl. 134: 287-295.

LAMPeRT, E. C., ZANGerl, A. R., Berenbaum, M. R., and Ode, P. J. 2008. Tritrophic effects of xanthotoxin on the polyembryonic parasitoid Copidosoma sosares (Hymenoptera: Encyrtidae). J. Chem. Ecol. 34: 783-790.

LAMPert, E. C., Dyer, L. A., and Bowers, M. D. 2010. Caterpillar chemical defense and parasitoid success: Cotesia congregata parasitism of Ceratomia catalpae. J. Chem. Ecol. 36: 992-998.

LAURENTZ, M. 2010. Diet quality can play critical role in the defence efficacy against parasitoids and pathogens in Glanville fritillary (Melitaea cinxia). Master Thesis. University of Jyväskylä.

LEATHER, S. R. 1988. Size, reproductive potential and fecundity in insects: things aren't as simple as they seem. Oikos 51: 386-389.

Lei, G. C., Vikberg, V., Nieminen, M., and KuUssaAri, M. 1997. The parasitoid complex attacking Finnish populations of the Glanville fritillary Melitaea cinxia (Lep: Nymphalidae), an endangered butterfly. J. Nat. Hist. 31: 635-648.

Li, X. C., Baudry, J., Berenbaum, M. R., and Schuler, M. A. 2004. Structural and functional divergence of insect CYP6B proteins: from specialist to generalist cytochrome P450. Proc. Natl. Acad. Sci. U.S.A. 101: 2939-2944.
Macel, M., Klinkhamer, P. G. L., VRieling, K., and VAn Der MEIJDEN, E. 2002. Diversity of pyrrolizidine alkaloids in Senecio species does not affect the specialist herbivore Tyria jacobaeae. Oecologia 133: 541-550.

Macel, M., Bruinsma, M., Dijkstra, S. M., OoijendiJK, T., NiEMEYER, H. M., and KlinKHAMER, P. G. L. 2005. Differences in effects of pyrrolizidine alkaloids on five generalist insect herbivore species. J. Chem. Ecol. 31: 1493-1508.

Mallampalli, N., Barbosa, P., and Weinges, K. 1996. Effects of condensed tannins and catalpol on growth and development of Compsilura concinnata (Diptera: Tachinidae) reared in gypsy moth (Lepidoptera: Lymantriidae). J. Entomol. Sci. 31: 289-300.

MaraK, H. B., Biere, A., and VAn Damme, J. M. M. 2000. Direct and correlated responses to selection on iridoid glycosides in Plantago lanceolata L. J. Evol. Biol. 13: 985-996.

MaraK, H. B., Biere, A., and VAn Damme, J. M. M. 2003. Fitness costs of chemical defense in Plantago lanceolata L.: Effects of nutrient and competition stress. Evolution 57: 2519-2530.

NAPPI, A. J. 1975. Parasite encapsulation in insects, pp. 293-356, in K. Maramoch and R. Shope, (eds.). Invertebrate Immunity. Academic Press, New York.

Nieminen, M., Suomi, J., Van Nouhuys, S., Sauri, P., and RIEKKOLA, M. L. 2003. Effect of iridoid glycoside content on oviposition host plant choice and parasitism in a specialist herbivore. J. Chem. Ecol. 29: 823-844.

NisHIDA, R. 2002. Sequestration of defensive substances from plants by Lepidoptera. Annu. Rev. Entomol. 47: 57-92.

ODE, P. J., 2006. Plant chemistry and natural enemy fitness: effects on herbivore and natural enemy interactions. Annu. Rev. Entomol. 51: $163-185$.

OJALA, K., JULKUnEN-Titto, R., Lindstrom, L., and MapPES, J. 2005. Diet affects the immune defence and life-history traits of an Arctiid moth Parasemia plantaginis. Evol. Ecol. Res. 7: 1153-1170.

PARAdise, C. J., and StAMP, N. E. 1993. Episodes of unpalatable prey reduce consumption and growth of juvenile praying mantids. $J$. Insect Behav. 6: 155-166.

Pereyra, P. C., and Bowers, M. D. 1988. Iridoid glycosides as oviposition stimulants for the buckeye butterfly, Junonia coenia (Nymphalidae). J. Chem. Ecol. 14: 917-928.

PutTicK, G. M., and Bowers, M. D. 1988. Effect of qualitative and quantitative variation in allelochemicals on generalist insects: iridoid glycosides and the southern army worm. J. Chem. Ecol. 14: 335-351.

Quicke, D. L. J. 1997. Parasitic wasps. Chapman and Hall, London. Renwick, J. A. A., Zhang, W. Q., Haribal, M., ATtygalle, A. B., and LOPEZ, K. D. 2001. Dual chemical barriers protect a plant against different larval stage of an insect. J. Chem. Ecol. 27: $1575-1583$.

Reudler TAlsma J. H. 2007. Costs and benefits or iridoid glycosides in multitrophic systems. Ph.D.dissertation. Wageningen University.

Reudler Talsma, J. H., Elzinga, J. A., Harvey, J. A., and Biere, A. 2007. Optimum and maximum host size at parasitism for the endoparasitoid Hyposoter didymator (Hymenoptera: Ichneumonidae) differ greatly between two host species. Environ. Entomol. 36: $1048-1053$.

Reudler Talsma, J. H., Biere A., Harvey, J. A., and Van Nouhuys, S. 2008. Oviposition cues for a specialist butterfly: plant chemistry and size. J. Chem. Ecol. 34: 1202-1212.

RHOADES, D. F. 1979. Evolution of plant chemical defense against herbivores. pp. 3-54, in Rosenthal G. A., and Janzen D. H. (eds.) Herbivores: Their Interaction with Secondary Plant Metabolites. Academic Press, New York.

SAASTAMOINEN, M. 2007. Life-history, genotypic, and environmental correlates of clutch size in the Glanville fritillary butterfly. Ecol. Entomol. 32: 235-242. 
SAastamoinen, M., Van Nouhuys, S., Nieminen, M., O’Hara, B., and SuOMI, J. 2007. Development and survival of a specialist herbivore, Melitaea cinxia, on host plants producing high and low concentrations of iridoid glycosides. Ann. Zool. Fenn. 44: $70-80$.

SAGAR, G. R., and HARPER, J. L. 1964. Biological flora of the British isles. Plantago major L., Plantago media L. and Plantago lanceolata L. J. Ecol. 52: 189-221.

Schneider, M. I., Smagghe, G., GobBi, A., and Viñuela, E. 2003. Toxicity and pharmacokinetics of insect growth regulators and other novel insecticides on pupae of Hyposoter didymator (Hymenoptera: Ichneumonidae), a parasitoid of early larval instars of Lepidopteran pests. J. Ecol. Entomol. 4: 1054-1065.

Singer, M. S. 2008. Evolutionary Ecology of Polyphagy. pp. 29-42, in Tilmon, K.J. (Ed.) Specialization, Speciation, and Radiation: The Evolutionary Biology of Herbivorous Insects. University of California Press, Berkeley, CA.

Smilanich, A. M., Dyer, L. A., Chambers, J. Q., and Bowers, M. D. 2009. Immunological cost of chemical defence and the evolution of herbivore diet breath. Ecol. Lett. 12: 612-621.

SuOmi, J., Sirén, H., Weidmer, S. K., and RiekKola, M. 2001. Isolation of aucubin and catalpol from Melitaea cinxia larvae and quantification by micellar electrokinetic capillary chromatography. Anal. Chim. Acta 429: 91-99.

SuOMI, J., Sirén, H., Jussila, M., Wiedner, S. K., and RieKKOlA, M. L. 2003. Determination of iridoid glycosides in larvae and adults of butterfly Melitaea cinxia by partial filling micellar electrokinetic capillary chromatography-electrospray ionisation mass spectrometry. Anal. Bioanal. Chem. 376: 884-889.

SZNAJDER, B., and HARVEY, J. A. 2003. Second and third trophic level effects of differences in plant species reflect dietary specialisation of herbivores and their endoparasitoids. Entomol. Exp. Appl. 109: 73-82.

Tingle, F. C., and Mitchell, E. R. 1977. Seasonal populations of armyworms and loopers at Hastings, Florida. Fla. Entomol. 60: $115-122$.

VAN NouHuYs, S., and PUnJu, E. 2010. Coexistence of competing parasitoids: which is the fugitive and where does it hide? Oikos 119: $61-70$

Van Nouhuys, S., Singer, M. C., and Nieminen, M. 2003. Spatial and temporal patterns of caterpillar performance and the suitability of two host plant species. Ecol. Entomol. 28: 193-202.

VINSON, S. B. 1990. Physiological interactions between the host genus Heliothis and its guild of parasitoids. Arch. Insect Biochem. 13: 63-81.

WiLSON, J. W. 1934. The asparagus caterpillar: its life history and control. Fla. Agr. Exp. Sta. Bull. 271: 1-26.

Wu, L., and ANTONOVICS, J. 1975. Experimental ecological genetics in Plantago. I. Induction of roots and shoots on leaves for large scale vegetative propagation and metal tolerance testing in $P$. lanceolata. New Phytol. 75: 277-282.

Zovi, D., Stastny, M., Battisti, A., and Larsson, S. 2008. Ecological costs on local adaptation of an insect herbivore imposed by host plants and enemies. Ecology 89: 1388-1398. 